\title{
Association between Thyroid Stimulating Hormone and Respiratory Distress Syndrome of Newborn in the Preterm Infants
}

Young Jin Kim

Wonju Severance Christian Hospital https://orcid.org/0000-0002-7694-7650

Byoung Kook Kim

Wonju Severance Christian Hospital

Yong Hyuk Kim ( $\nabla$ sumergo@yonsei.ac.kr)

https://orcid.org/0000-0001-6705-4730

Research article

Keywords: preterm infant, pulmonary surfactant, respiratory distress syndrome of newborn, thyroid hormone

Posted Date: July 7th, 2020

DOI: https://doi.org/10.21203/rs.3.rs-40381/v1

License: (a) (1) This work is licensed under a Creative Commons Attribution 4.0 International License. Read Full License 


\section{Abstract}

Background: Various hormones are known to influence the production and secretion of pulmonary surfactant. But the relationship between respiratory distress syndrome (RDS) and thyroid hormone has yet to be clarified.

Methods: 126 infants with gestational age between 24 and 34 weeks who were hospitalized at the neonatal ICU of the Wonju Severance Christian Hospital from April 2017 to February 2019 were included in the study. Infants were divided into 3 groups by gestational age -24 weeks 0 days to 28 weeks 0 days, 28 weeks 0 days to 31 weeks 0 days, and 31 weeks 0 days to 33 weeks 0 days, each with 18, 34, and 74 subjects, respectively. Among the subjects, there were 56 infants with RDS and 70 infants without RDS.

Results: The group with lowest gestational age showed $\mathrm{T}_{3}$ and $\mathrm{fT}_{4}$ level that was lower than those of other groups $(p<0.05)$ on the day of birth but there was no difference in the TSH level $(p=0.129) . T_{3}$ and TSH level were lower in the RDS group compared with the control group on the day of birth $(p<0.05)$. Free thyroxine $\left(\mathrm{fT}_{4}\right)$ level was higher in the control group on the day of birth but without any significant difference. Multiple logistic regression analysis showed that lower serum TSH levels on the day of birth was associated with a higher incidence of RDS $(p<0.05)$.

Conclusion: The incidence of RDS was significantly higher in infants with lower serum TSH levels at birth, but there was no significant difference in RDS incidence according to serum thyroid hormone levels.

\section{Background}

Respiratory distress syndrome (RDS) is a disease caused by inadequate production of pulmonary surfactant and structural immaturity of the lung. Although various treatment methods are available, it is still a major cause of morbidity and mortality in premature infants [1]. Risk factors affecting the incidence of RDS are known to include prematurity, low birth weight, maternal diabetes, multiple births, cesarean delivery, precipitous delivery, asphyxia, cold stress, and maternal history of previously affected infants, etc [2]. Various hormones are known to influence the production and secretion of surfactant and cortisol is one of them. In 1994, Srivastava et al. [3] reported that lower blood cortisol levels were associated with respiratory distress syndrome (RDS) in premature infants.

In addition to above, fetal lung maturation and pulmonary surfactant secretion are reported to be affected by various hormones including glucocorticoid, estrogen, prolactin, and insulin [4-6].

In 1998, Ballard et al. [7] reported through animal studies that thyroid hormone promotes fetal lung maturation and has a synergistic effect with glucocorticoid. Subsequently, antenatal thyrotropin-releasing hormone was administered to prevent RDS and chronic lung disease in mothers at risk of preterm birth but no significant results were obtained; instead, side effects such as delayed development was reported. However, in 2013, Torkaman et al. [8] reported the association with RDS while analyzing the TSH and free 
between thyroid stimulating hormone and RDS. In addition, Tanaka et al. [10] reported in 2007 that the TSH surge caused by the stress during birth improves surfactant production.

In this study, we analyzed $T_{3}$, free $T_{4}$, and TSH levels according to gestational age in prematurity to analyze the relationship between hormones levels and RDS.

\section{Methods}

\section{Patients}

This study was conducted as a retrospective analysis by reviewing medical records of premature infants aged between 24 weeks 0 days and 34 weeks 0 days in gestational age who were born at Wonju Severance Christian Hospital of South Korea between April 2017 and February 2019. During this period, total of 140 premature infants were born and those who had congenital anomaly, congenital hypothyroidism, or were outborn, or lost to follow up were excluded. Triiodothyronine $\left(T_{3}\right)$, free thyroxine $\left(\mathrm{fT}_{4}\right)$, and thyroid stimulating hormone $(\mathrm{TSH})$ were measured in these premature infants by collecting cord blood on the day of birth. The same thyroid function test was repeated by sampling venous blood on days 7, 21 and 42 from birth.

\section{Measurements}

Serum TSH levels were measured using chemiluminescent enzyme immunoassay (CLEIA) (Atellica solution IM analyzer, Siemens, Berlin, Germany). This method is structured as follows. 1) AntiFITC(Fluorescein isothiocyanate) monoclonal antibody covalently bonded to paramagnetic particle. 2) FITC-labeled anti-TSH capture monoclonal antibody. 3) Acridinum ester and tracer consisting of anti-TSH monoclonal antibody bound to bovine serum albumin for chemiluminescence detection. TLE can be detected from the lower limit of $0.008 \mathrm{ulU} / \mathrm{mL}$ to $150.000 \mathrm{ulU} / \mathrm{mL}$ by CLEIA analysis.

Serum $\mathrm{T}_{3}$ and $\mathrm{fT}_{4}$ levels were also measured competitively using chemiluminescent enzyme immunoassay (CLEIA). In this method, $\mathrm{T}_{3} / \mathrm{fT}_{4}$ and $\mathrm{T}_{3}$ analogues covalently bound to the paramagnetic particles of the sample compete with limited acridinium ester-labeled monoclonal mouse anti- $\mathrm{T}_{3} / \mathrm{fT}_{4}$ antibodies.

In this assay, $T_{3}$ can be detected from the lower limit of $0.10 \mathrm{ng} / \mathrm{mL}$ to the upper limit of $8.00 \mathrm{ng} / \mathrm{mL}$ and $\mathrm{fT}_{4}$ can be detected from $0.1 \mathrm{ng} / \mathrm{dL}$ to the upper limit of $12.0 \mathrm{ng} / \mathrm{dL}$.

In addition, patient information including maternal age, gestational age, birth weight, delivery, sex, multiple pregnancy, APGAR score, antenatal steroid, maternal GDM, maternal PIH, pathologic chorioamnionitis, PPROM, maternal thyroid disease, PDA, RDS, BPD, NEC, PVL, IVH, pulmonary hypertension, retinopathy of prematurity with panretinal photocoagulation, hypothyroidism, and death was collected retrospectively using electronic medical records for analysis. 
The mean values of $\mathrm{T}_{3}$, free $\mathrm{T}_{4}$, and $\mathrm{TSH}$ were compared by grouping the babies according to gestational age into 24 weeks 0 days to 27 weeks 0 days, 27 weeks 0 days to 30 weeks 6 days, and 31 weeks 0 days to 34 weeks 0 days.

RDS was defined as the cases where surfactant was administered for typical findings of RDS such as air bronchogram in chest $\mathrm{x}$-ray, required at least $40 \% \mathrm{FiO}_{2}$ respiratory assistance and showed respiratory distress symptoms such as chest retraction, and nasal flaring. Accordingly, patient-control analysis was conducted by grouping the premature babies into those who had RDS and those who did not.

\section{Ethics Statements}

The study was approved by the Ethics Committee of Yonsei University Wonju College of Medicine (approval number CR320012). The need for informed consent was waived owning to the retrospective nature of the study.

\section{Statistical analysis}

For data analysis, Statistical Package for the Social Science (SPSS Inc,. Chicago, IL,USA) was used. Continuous variables were analyzed using independent t-test, the Mann-Whitney test, one-way ANOVA and repeated measures ANOVA while non-continuous variables were analyzed using $x^{2}$ or Fisher's exact test. All values were expressed as mean \pm 1 standard deviation. P-value for statistical significance was < 0.05 .

In order to analyze the association between the incidence of RDS and $\mathrm{T}_{3}$ and TSH, multiple logistic regression was performed with stepwise selection. The 5-minute APGAR score, birth weight, and gestational age were analyzed as the interaction variables. P-value for statistical significance was $<0.05$.

\section{Results}

Among 140 premature infants with gestational age between 24 weeks 0 days and 34 weeks 0 days who were hospitalized at the neonatal ICU of the Wonju Severance Christian Hospital from April 2017 to February 2019, 126 infants were included in the study excluding 3 with congenital anomaly, 6 with congenital hypothyroidism, 3 who were outborn, and 3 who were lost to follow up (Fig. 1). Infants were divided into 3 groups by gestational age - 24 weeks 0 days to 28 weeks 0 days, 28 weeks 0 days to 31 weeks 0 days, and 31 weeks 0 days to 33 weeks 0 days, each with 18, 34, and 74 subjects, respectively. Among the subjects, there were 56 infants with RDS and 70 infants without RDS. 
Table 1

Infant and maternal characteristics according to gestational age by one-way ANOVA

\begin{tabular}{|c|c|c|c|c|c|}
\hline Variable & $\begin{array}{l}\text { Total } \\
(n=126)\end{array}$ & $\begin{array}{l}\text { 24-27weeks } \\
(n=18)\end{array}$ & $\begin{array}{l}\text { 28-30weeks } \\
(n=34)\end{array}$ & $\begin{array}{l}\text { 31-33weeks } \\
(n=74)\end{array}$ & $p$ \\
\hline Gestational age (weeks) & $30.44 \pm 2.45$ & $25.83 \pm 1.10$ & $29.09 \pm 0.87$ & $32.18 \pm 0.73$ & 0.000 \\
\hline Birth weight (gram) & $1544 \pm 446$ & $822 \pm 141$ & $1321 \pm 247$ & $1822 \pm 279$ & 0.000 \\
\hline C-sec delivery & $97(77.0)$ & $14(77.8)$ & $25(73.5)$ & $58(78.4)$ & 0.857 \\
\hline Labor pain & $93(73.8)$ & $12(66.7)$ & $26(76.5)$ & $55(74.3)$ & 0.745 \\
\hline \multicolumn{6}{|l|}{ Sex } \\
\hline Male & $55(43.7)$ & $10(55.6)$ & $15(44.1)$ & $30(40.5)$ & 0.520 \\
\hline Female & $71(56.3)$ & $8(44.4)$ & $19(55.9)$ & $44(59.5)$ & 0.520 \\
\hline Multiples & $31(24.6)$ & $2(11.1)$ & $6(17.7)$ & $23(31.1)$ & 0.262 \\
\hline SGA & $3(2.4)$ & $0(0.0)$ & $1(2.9)$ & $2(2.7)$ & 0.776 \\
\hline APGAR at $5 \mathrm{~min}$ & $7.79 \pm 1.57$ & $6.50 \pm 1.62$ & $7.38 \pm 1.41$ & $8.28 \pm 1.41$ & 0.000 \\
\hline Maternal age & $32.72 \pm 5.82$ & $33.94 \pm 6.48$ & $30.82 \pm 6.56$ & $33.30 \pm 5.14$ & 0.076 \\
\hline GDM & $19(15.1)$ & $2(11.1)$ & $2(5.9)$ & $15(20.3)$ & 0.136 \\
\hline Preeclampsia & $27(21.4)$ & $4(22.2)$ & $5(14.7)$ & $18(24.3)$ & 0.532 \\
\hline PPROM & $63(50.4)$ & $8(44.4)$ & $19(55.9)$ & $36(49.3)$ & 0.710 \\
\hline Pathologic chorioamnionitis & $50(44.6)$ & $8(44.4)$ & $13(41.9)$ & $29(46.0)$ & 0.933 \\
\hline Maternal thyroid disease & $0(0.0)$ & $0(0.0)$ & $0(0.0)$ & $0(0.0)$ & 1.000 \\
\hline \multicolumn{6}{|l|}{ Antenatal steroid } \\
\hline Not injected & $23(18.4)$ & $3(16.7)$ & $6(17.6)$ & $14(19.2)$ & 0.963 \\
\hline Incomplete & $44(35.2)$ & $8(44.4)$ & $9(26.5)$ & $27(37.0)$ & 0.390 \\
\hline Complete & $58(46.4)$ & $7(38.9)$ & $19(55.9)$ & $32(43.8)$ & 0.407 \\
\hline \multicolumn{6}{|c|}{ Number $(\%)$ or mean $( \pm S D)$ shown } \\
\hline \multicolumn{6}{|c|}{$\begin{array}{l}\text { SD, Standard deviation; SGA, Small for gestational age; GDM, Gestational diabetes mellitus; PPROM, } \\
\text { Preterm premature rupture of membrane }\end{array}$} \\
\hline
\end{tabular}

Table 1 shows the baseline characteristics of the groups according to gestational age. The mean gestational age of the subjects was $30.44 \pm 2.45$ weeks and the mean birth weight was $1544 \pm 446 \mathrm{~g}$. When they were divided into 3 groups by gestational age into 24 weeks 0 days to 28 weeks 0 days, 28 Loading [MathJax]/jax/output/CommonHTML/jax.js eeks 0 days to 33 weeks 0 days, the mean gestational age 
was $25.83 \pm 1.10$ weeks, $29.09 \pm 0.87$ weeks, and $32.18 \pm 0.73$ weeks, while the mean birth weight was $822 \pm 141 \mathrm{~g}, 1321 \pm 247 \mathrm{~g}$, and $1822 \pm 279 \mathrm{~g}$, respectively. The 5-minute APGAR score was found to be lower for lower gestational age with $6.50 \pm 1.62,7.38 \pm 1.41$, and $8.28 \pm 1.41$ for gestational age of 24 weeks 0 days to 28 weeks 0 days, 28 weeks 0 days to 31 weeks 0 days, and 31 weeks 0 days to 33 weeks 0 days, respectively $(p<0.05)$. When intergroup comparison was made according to gestational age, there was no difference depending on the delivery method, sex, multiple births, or SGA but the 5-minutes APGAR score tended to be lower for the group with lower gestational age $(p<0.05)$. There was no difference among the groups according to gestational age depending on maternal age, gestational diabetes mellitus, PPROM, pathologic chorioamnionitis, maternal thyroid disease and antenatal steroid use.

Figure 2 shows the serum thyroid hormone level at the time of birth, 1 week after birth, 3 weeks after birth and 6 weeks after birth according to gestational age. Serum $T_{3}$ level tended to increase in all groups until up to 6 weeks after birth. The group with gestational age of 24 weeks 0 days to 28 weeks 0 days showed $\mathrm{T}_{3}$ level that was significantly lower than those of other groups with $0.32 \pm 0.07 \mathrm{ng} / \mathrm{mL}, 0.53 \pm$ $0.24 \mathrm{ng} / \mathrm{mL}, 0.64 \pm 0.27 \mathrm{ng} / \mathrm{mL}$, and $0.84 \pm 0.24 \mathrm{ng} / \mathrm{mL}$ on the day of birth, and 1,3 and 6 weeks after birth, respectively $(p<0.05)$. Serum fT4 level was shown to be lower for the group with gestational age of 24 weeks 0 days to 28 weeks 0 days compared to other groups $(p<0.05)$ with $0.90 \pm 0.15 \mathrm{ng} / \mathrm{mL}$ and $1.03 \pm 0.34 \mathrm{ng} / \mathrm{mL}$ on the day of birth and 1 week after birth, respectively; however, there was no significant difference according to gestational age from 3 weeks after birth. The serum TSH level measured on the day of birth tended to be lower for the group with lower gestational age but there was no significant differences among the groups $(p=0.129)$.

As shown in Fig. 2, triiodothyronine $\left(\mathrm{T}_{3}\right)$ level was lower in groups with lower gestational age compared to other groups on the day of birth, and 1, 3 and 6 weeks after birth. Free thyroxine ( $\left.\mathrm{fT}_{4}\right)$ was significantly lower in the group with lower gestational age on the day of birth and 1 week after birth but there was no difference in the thyroid stimulating hormone (TSH) level on the day of birth among the groups. 
Table 2

Infant and maternal characteristics by presence of RDS

\begin{tabular}{|c|c|c|c|}
\hline Variable & $\begin{array}{l}\text { RDS } \\
(n=56)\end{array}$ & $\begin{array}{l}\text { Control } \\
(n=70)\end{array}$ & $p$ \\
\hline Gestational age (weeks) & $29.02 \pm 2.61$ & $31.57 \pm 1.58$ & 0.000 \\
\hline Birth weight (gram) & $1353 \pm 510$ & $1697 \pm 315$ & 0.000 \\
\hline C-sec delivery & $46(82.1)$ & $51(72.9)$ & 0.219 \\
\hline Labor pain & $39(69.6)$ & $54(71.1)$ & 0.227 \\
\hline \multicolumn{4}{|l|}{ Sex } \\
\hline Male & $24(42.9)$ & $31(44.3)$ & 0.872 \\
\hline Female & $32(57.1)$ & $39(55.7)$ & 0.872 \\
\hline Multiples & $11(19.7)$ & $22(28.6)$ & 0.085 \\
\hline Small for gestational age & $1(1.8)$ & $2(2.9)$ & 0.695 \\
\hline APGAR at $5 \mathrm{~min}$ & $6.89 \pm 1.65$ & $8.50 \pm 1.07$ & 0.000 \\
\hline Maternal age & $32.66 \pm 6.88$ & $32.77 \pm 4.86$ & 0.916 \\
\hline GDM & $7(12.5)$ & $12(17.1)$ & 0.618 \\
\hline Preeclampsia & $15(26.8)$ & $12(17.1)$ & 0.199 \\
\hline PPROM & $23(41.1)$ & $40(58.0)$ & 0.073 \\
\hline Pathologic chorioamnionitis & $18(36.0)$ & $32(51.6)$ & 0.072 \\
\hline Maternal thyroid disease & $0(0.0)$ & $0(0.0)$ & 1.000 \\
\hline \multicolumn{4}{|l|}{ Antenatal steroid } \\
\hline Not injected & $9(16.1)$ & $14(20.3)$ & 0.357 \\
\hline Incomplete & $23(41.1)$ & $21(30.4)$ & 0.147 \\
\hline Complete & $24(42.9)$ & $34(49.3)$ & 0.296 \\
\hline \multicolumn{4}{|c|}{ Number $(\%)$ or mean $( \pm \mathrm{SD})$ shown } \\
\hline \multicolumn{4}{|c|}{$\begin{array}{l}\text { SD, Standard deviation; SGA, Small for gestational age; GDM, Gestational diabetes mellitus; PPROM, } \\
\text { Preterm premature rupture of membrane }\end{array}$} \\
\hline
\end{tabular}

Table 2 shows the baseline characteristics of the RDS and the control groups. The mean gestational age of the RDS group was $29.02 \pm 2.61$ weeks and birth weight was $1353 \pm 510 \mathrm{~g}$. For the control group, the mean gestational age was $31.57 \pm 1.58$ weeks and birth weight was $1697 \pm 315 \mathrm{~g}$, showing a significant Loading [MathJax]/jax/output/CommonHTML/jax.js e 5-minute APGAR score was significantly lower in the RDS 
group with $6.89 \pm 1.65(p<0.05)$ but there was no difference among the groups according to the delivery method, presence of labor prior to birth, sex, multiple births, and whether or not they were SGA. In addition, no difference was observed in maternal age, gestational diabetes mellitus, PPROM, pathologic chorioamnionitis and antenatal steroid use depending on the presence of RDS. There was no case of maternal thyroid disease in the RDS or the control group.

Table 3

Morbidity and mortality of infant by presence of RDS

\begin{tabular}{|c|c|c|c|}
\hline Variable & $\begin{array}{l}\text { RDS } \\
(n=56)\end{array}$ & $\begin{array}{l}\text { Control } \\
(n=70)\end{array}$ & $p$ \\
\hline BPD & $28(50.0)$ & $6(8.6)$ & 0.000 \\
\hline PDA (Therapeutic) & $15(26.8)$ & $2(2.9)$ & 0.000 \\
\hline Pulmonary hypertension & $5(8.9)$ & $1(1.4)$ & 0.061 \\
\hline NEC & $9(16.1)$ & $1(1.4)$ & 0.030 \\
\hline PVL & $1(1.8)$ & $1(1.4)$ & 0.693 \\
\hline IVH & $0(0.0)$ & $1(1.4)$ & 0.556 \\
\hline ROP with PRP & $5(8.9)$ & $1(1.4)$ & 0.061 \\
\hline Death & $2(3.6)$ & $0(0.0)$ & 0.196 \\
\hline \multicolumn{4}{|c|}{ Number $(\%)$ or mean $( \pm \mathrm{SD})$ shown } \\
\hline \multicolumn{4}{|c|}{$\begin{array}{l}\text { RDS, Respiratory distress syndrome; BPD, Bronchopulmonary dysplasia; PDA, Patent ductus } \\
\text { arteriosus; NEC, Necrotizing enterocolitis; PVL, Periventricular leukomalacia; IVH, Intraventricular } \\
\text { hemorrhage; ROP with PRP, Retinopathy of prematurity with Panretinal photocoagulation }\end{array}$} \\
\hline
\end{tabular}

As seen in Table 3, neonatal morbidity was higher for BPD, PDA requiring treatment and NEC in the RDS group compared to the control group $(p<0.05)$ but no difference was observed for pulmonary hypertension, periventricular leukomalacia, intraventricular hemorrhage, and retinopathy of prematurity with panretinal photocoagulation. There was no difference in mortality between the RDS and the control groups $(p=0.196)$. 
Table 4

Thyroid hormone level by presence of RDS

\begin{tabular}{|c|c|c|c|}
\hline Variable & $\begin{array}{l}\text { RDS } \\
(n=72)\end{array}$ & $\begin{array}{l}\text { Control } \\
(n=60)\end{array}$ & $p$ \\
\hline \multicolumn{4}{|l|}{$\mathrm{T}_{3}(\mathrm{ng} / \mathrm{mL})$} \\
\hline At birth & $0.39 \pm 0.18$ & $0.49 \pm 0.12$ & 0.001 \\
\hline At 1st week & $0.71 \pm 0.25$ & $0.94 \pm 0.21$ & 0.000 \\
\hline At 3rd week & $0.83 \pm 0.27$ & $1.10 \pm 0.23$ & 0.000 \\
\hline At 6th week & $1.02 \pm 0.32$ & $1.24 \pm 0.26$ & 0.001 \\
\hline \multicolumn{4}{|l|}{$\mathrm{fT}_{4}(\mathrm{ng} / \mathrm{mL})$} \\
\hline At birth & $1.05 \pm 0.23$ & $1.12 \pm 0.18$ & 0.088 \\
\hline At 1st week & $1.36 \pm 0.39$ & $1.48 \pm 0.27$ & 0.039 \\
\hline At 3rd week & $1.39 \pm 0.26$ & $1.33 \pm 0.18$ & 0.165 \\
\hline At 6th week & $1.29 \pm 0.19$ & $1.24 \pm 0.19$ & 0.280 \\
\hline \multicolumn{4}{|c|}{ TSH (|varvec $\mu \mid \mathrm{lU} / \mathrm{mL})$} \\
\hline At birth & $7.13 \pm 3.55$ & $9.63 \pm 7.92$ & 0.048 \\
\hline At 1st week & $4.71 \pm 3.26$ & $4.41 \pm 2.59$ & 0.563 \\
\hline At 3rd week & $6.38 \pm 4.67$ & $4.20 \pm 2.74$ & 0.002 \\
\hline At 6th week & $4.44 \pm 3.49$ & $3.63 \pm 2.90$ & 0.248 \\
\hline \multicolumn{4}{|c|}{ Mean $( \pm S D)$ shown } \\
\hline \multicolumn{4}{|c|}{$\mathrm{T}_{3}$, Triiodothyronine; $\mathrm{fT}_{4}$, Free thyroxine; $\mathrm{TSH}$, Thyroid stimulating hormone } \\
\hline
\end{tabular}

In the comparison of serum thyroid hormone level according to the presence of RDS (Table 4), the RDS group showed an increasing tendency for serum $T_{3}$ level from the day of birth to week 6 but the levels were still significantly lower compared to those of the control group with $0.39 \pm 0.18 \mathrm{ng} / \mathrm{mL}, 0.71 \pm$ $0.25 \mathrm{ng} / \mathrm{mL}, 0.83 \pm 0.27 \mathrm{ng} / \mathrm{mL}$, and $1.02 \pm 0.32 \mathrm{ng} / \mathrm{mL}$ on the day of birth, and 1,3 , and 6 weeks after birth, respectively $(p<0.05)$. There was no difference among the groups in serum $\mathrm{fT}_{4}$ level on the day of birth but serum TSH level was confirmed to be significantly lower in the RDS group compared to that of the control group $(7.13 \pm 3.55 \mathrm{uiU} / \mathrm{mL}$ versus $9.63 \pm 7.92 \mathrm{uiU} / \mathrm{mL}, p<0.05)$.

As shown in Fig. 3, triiodothyronine $\left(T_{3}\right)$ level showed an increase until 6 weeks after birth but the levels were lower in the RDS group compared with the control group on the day of birth, and 1, 3, and 6 weeks Loading [MathJax]/jax/output/CommonHTML/jax.js her in the control group on the day of birth but without any 
significant difference. Thyroid stimulating hormone $(\mathrm{TSH})$ level was higher in the RDS group on the day of birth but there was no significant difference 1 week after birth.

Table 5

Effect of the predictors of presence of respiratory distress syndrome: Multivariate logistic regression analysis

\begin{tabular}{|lllll|}
\hline Predictor & $\boldsymbol{\beta}$ coefficient & $\boldsymbol{P \text { value }}$ & Odd ratio & $\mathbf{9 5 \%} \mathbf{C l}$ \\
\hline Gestational age & -0.72 & 0.004 & 0.49 & $0.298-0.790$ \\
\hline Birth weight & 2.24 & 0.060 & 9.35 & $0.910-96.127$ \\
\hline APGAR at 5 min & -0.93 & 0.000 & 0.40 & $0.236-0.659$ \\
\hline $\mathrm{T}_{3}$ at birth & -2.59 & 0.155 & 0.08 & $0.002-2.649$ \\
\hline TSH at birth & -0.12 & 0.014 & 0.89 & $0.803-0.976$ \\
\hline 95\% Cl, 95\% confidence interval; $\mathrm{T}_{3}$, Triiodothyronine, $\mathrm{TSH}$, Thyroid stimulating hormone \\
\hline
\end{tabular}

Table 5 shows the results of multiple logistic regression analysis on RDS by controlling gestational age, birth weight, 5-minute APGAR, and serum $\mathrm{T}_{3}$ as well as TSH levels on the day of birth. It was demonstrated that lower gestational age (OR 0.486, 95\% Cl 0.298-0.790), lower 5-minute APGAR (OR $0.395,95 \% \mathrm{Cl} 0.236-0.659)$, and lower serum TSH levels on the day of birth (OR $0.885,95 \% \mathrm{Cl} 0.803-$ $0.976)$ was associated with a higher incidence of RDS $(p<0.05)$. On the other hand, birth weight and serum $\mathrm{T}_{3}$ level on the day of birth did not show significant results in terms of RDS incidence.

\section{Discussion}

The authors confirmed that the serum TSH and thyroid hormone levels immediately after birth were significantly lower in RDS patients $(p<0.05)$. After birth, significant changes occur in the thyroid hormone axis in newborns. Within 30 minutes of birth, up to $70 \mathrm{mcU} / \mathrm{L}$ of $\mathrm{TSH}$ is secreted due to the stimulus to changes in environmental temperature. This phenomenon is called TSH surge, which stimulates the thyroid to increase serum $T_{3}$ and $T_{4}$ levels. As a result, serum $T_{4}$ levels increase to the highest levels in life, and then slowly decrease after one week of life $[11,12]$. TSH surges occur not only in full term infants but also in premature infants. However, the lower the gestational age, the lower the body weight, and the more fetal complications, the lower the degree of TSH surge and the more delay in timing [13]. However, little is known about the association between RDS and the hypothalamic-pituitary-thyroid axis. The study conducted by Tanaka et al. [10] in attempt to clarify this showed that TSH levels tended to be lower in the RDS group than in the control group, but there was no significant difference. In this study, serum TSH levels were significantly lower in the RDS group than in the control group $(7.13 \pm 3.55$ versus $9.63 \pm 7.92$, respectively). The low serum TSH level measured immediately after birth when TSH surge should occur is thought to reflect the immaturity of the hypothalamic-pituitary-thyroid axis, particularly endocrine 
In a previous study, Ballard et al. [7] reported that lung maturation was delayed due to low TSH surge and the resulting low serum thyroid hormone level in premature infants, leading to an increase in RDS.

In newborns, RDS is a disease in which the insufficient production and secretion of surfactant in type II pneumocytes due to immaturity act as the primary factor, resulting in decreased lung compliance and increased airway resistance, and respiratory distress persists due to the development of atelectasis and hypoxia. Lung surfactant, the most important cause of RDS, is composed of saturated phosphatidylcholine, phosphatidylglycerol, and surfactant protein. Blood pH, body temperature, and perfusion have major effects on the production and secretion of lung surfactant but many other endocrine factors are known to have an effect as well. Fetal lung maturation is affected by the interactions of various hormones. Previous studies have shown that corticosteroids, thyroid hormones, $\mathrm{TRH}$, prolactin, catecholamine, cAMP, r-interferon, estrogen, and epidermal growth factors stimulate or promote lung maturation, and androgen, insulin, and TGF-B delay lung maturation.

Of these, the thyroid hormone acts on the lungs of the fetus through a receptor-mediated response and increases surfactant production and type II pneumocytes, but $T_{4}$ does not affect the activity of enzymes involved in phosphatidylcholine production. Therefore, $T_{4}$ is thought to promote the translocation of lipids into the lamellar body and increase the influx of phosphatidylcholine precursors to facilitate fetal lung maturation [4]. Based on this, there were studies to prevent RDS of premature infants by administering TRH but no significant results were obtained and the premature infants given TRH experienced adverse consequences such as neurodevelopmental delay [7].

The association between RDS and hormones other than the thyroid hormone is also being studied. It is well known that hypothalamic-pituitary-adrenal gland axis in the fetus affects lung surfactant metabolism [14]. AJ Chu confirmed that estrogen stimulates the synthesis and production of lung surfactants [15], and Engle $\mathrm{M} \mathrm{J}$ reported that low dose insulin increased the synthesis of lung surfactants [16].

As such, the authors thought that functional immaturity of the hypothalamus caused RDS by reducing the production and secretion of lung surfactant by causing a decrease in the secretion of various hormones that should increase during the perinatal period.

TRH is secreted from gestational age of 8 weeks and TSH is secreted from gestational age of 12 weeks. The secretion ability in the hypothalamus and pituitary gland is present from the first trimester of pregnancy, but the feedback function of maturation actually takes up to three months after birth [17]. This also supports the unstable hormonal function in premature infants. This endocrine prematurity persists for a certain period of time after birth, and in premature infants with RDS, $T_{4}$ decreases after one week of birth, and gradually increases, approaching the level of full-term infants by six weeks of age [18]. In the present study, $\mathrm{fT}_{4}$ at 1 week of age was lower in the RDS group, but the normal level was recovered subsequently ( $1.36 \pm 0.39$ versus $1.48 \pm 0.28$, respectively). 
Thyroid gland is formed at 7 weeks of gestational age, but $T_{3}$ and $T_{4}$ can be secreted from 12 weeks of gestational age. However, until mid-pregnancy, $T_{4}$ is mainly produced and the concentration of $T_{3}$ remains relatively low, as also confirmed in this study. Shortly after birth, $\mathrm{T}_{3}$ and $\mathrm{fT}_{4}$ levels were lower for younger gestational ages. However, as gestational age increased, infants with low gestational age had lower $\mathrm{T}_{3}$ but the significant difference in $\mathrm{fT}_{4}$ disappeared over time [19].

Ballard et al. analyzed that TSH increased choline incorporation and production, and that glucocorticoid increased surfactant production and concentration [7]. This suggests that surfactant secretion is affected by the regulation of various hormones. A study by Fisher et al. [20] reported that fetal serum TSH increased from second to third trimester indicating functional maturation of hypothalamus and pituitary gland. Therefore, the low serum TSH level in the RDS group of the present study is thought to be due to the relatively immature hypothalamic-pituitary function compared to the control group. Thus, the authors thought that the immature hypothalamic-pituitary function is one of the causes of RDS and not the result of RDS, but additional research would be needed to confirm this.

The strength of this study was that all subjects were assessed by a single neonatologist in a single center and were evaluated continuously for a regular period of time up to 6 weeks after birth. It was rather homogenous in that there was a relatively uniform assessment on the areas where disagreement could have existed among physicians, such as the diagnosis of APGAR scores or RDS, and that regular thyroid hormone evaluations were made under a single treatment policy at a single center. Due to the fact that it

is a single center study, the small sample number is considered as the limitation of this study which could be supplemented by additional studies with a larger number of samples.

\section{Conclusion}

The incidence of RDS was significantly higher in infants with lower serum TSH levels at birth, but there was no significant difference in RDS incidence according to serum thyroid hormone levels. The serum TSH level at birth reflects TSH surge, which indicates maturation of the hypothalamic-pituitary-thyroid axis. Thus, inhibition of hormones due to immaturity at the hypothalamic-pituitary level, not at the thyroid level, may be considered as a cause of RDS by inhibiting the secretion of surfactant in type II pneumocytes. Based on this, additional research is needed to identify various hormones that affect the development of RDS.

\section{Abbreviations}

BPD: Bronchopulmonary dysplasia; Cl: Confidence interval; GDM: Gestational diabetes mellitus; IVH: Intraventricular hemorrhage; NEC: Necrotizing enterocolitis; PDA: Patent ductus arteriosus; PVL: Periventricular leukomalacia; RDS: Respiratory distress syndrome; SGA: Small for gestational age; TSH: Thyroid stimulating hormone; $\mathrm{T}_{3}$ : Triiodothyronine; $\mathrm{fT}_{4}$ : Free thyroxine 


\section{Ethics approval and consent to participate}

The study was approved by the Ethics Committee of Yonsei University Wonju College of Medicine (approval number CR320012). The need for informed consent was waived owning to the retrospective nature of the study.

\section{Consent to publish}

Not applicable.

\section{Availability of data and materials}

All authors declare that data and any supporting material regarding this manuscript are available and can be requested at any time.

\section{Competing interest}

The authors declare that there is no competing interest.

\section{Funding}

The authors received no specific funding for this work.

\section{Authors' contributions}

All authors have read and approved to manuscript. Kim YH, Kim YG and Lee BK contributed to the concept, design, data collection, analysis and literature search.

\section{Acknowledgements}

Not applicable

\section{References}

1. Sweet DG, Carnielli V, Greisen G, et al. European Consensus Guidelines on the Management of Respiratory Distress Syndrome - 2019 Update. Neonatology. 2019;115:432-50.

2. Altman $M$, Vanpee $M$, Cnattingius $S$, Norman $M$. Risk factors for acute respiratory morbidity in mnderatelv nreterm infantc Paediatr Perinat Epidemiol. 2013;27:172-81. 
3. Srivastava T, Merchant RH, Ambadekar MC. Cord blood cortisol levels and respiratory distress syndrome. Indian Pediatr. 1994;31:923-8.

4. Akella A, Deshpande SB. Pulmonary surfactants and their role in pathophysiology of lung disorders. Indian J Exp Biol. 2013;51:5-22.

5. Redding RA, Pereira C. Thyroid function in respiratory distress syndrome (RDS) of the newborn. Pediatrics. 1974;54:423-8.

6. Klein AH, Foley B, Foley TP, MacDonald HM, Fisher DA. Thyroid function studies in cord blood from premature infants with and without RDS. J Pediatr. 1981;98:818-20.

7. Ballard RA, Ballard PL, Cnaan A, et al. Antenatal thyrotropin-releasing hormone to prevent lung disease in preterm infants. North American Thyrotropin-Releasing Hormone Study Group. N Engl J Med. 1998;338:493-8.

8. Torkaman M, Ghasemi F, Amirsalari S, et al. Thyroid Function Test in Pre-term Neonates During the First Five Weeks of Life. Int J Prev Med. 2013;4:1271-6.

9. Ryckman KK, Spracklen CN, Dagle JM, Murray JC. Maternal factors and complications of preterm birth associated with neonatal thyroid stimulating hormone. J Pediatr Endocrinol Metab. 2014;27:929-38.

10. Tanaka K, Shimizu T, Hosaka A, Tokita A, Shiga S, Yamashiro Y. Serum free T4 and thyroid stimulating hormone levels in preterm infants and relationship between these levels and respiratory distress syndrome. Pediatr Int. 2007;49:447-51.

11. Feingold SB, Brown RS. Neonatal Thyroid Function. NeoReviews. 2010;11:e640-e6.

12. Biswas S, Buffery J, Enoch H, Bland JM, Walters D, Markiewicz M. A Longitudinal Assessment of Thyroid Hormone Concentrations in Preterm Infants Younger Than 30 Weeks' Gestation During the First 2 Weeks of Life and Their Relationship to Outcome. Pediatrics. 2002;109:222-7.

13. LaFranchi S. Thyroid function in the preterm infant. Thyroid. 1999;9:71-8.

14. Murphy $\mathrm{N}$, Hume R, van Toor $\mathrm{H}$, et al. The hypothalamic-pituitary-thyroid axis in preterm infants; changes in the first 24 hours of postnatal life. J Clin Endocrinol Metab. 2004;89:2824-31.

15. Chu AJ, Rooney SA. Estrogen stimulation of surfactant synthesis. Pediatr Pulmonol. 1985;1:S110-4.

16. Engle MJ, Langan SM, Sanders RL. The effects of insulin and hyperglycemia on surfactant phospholipid synthesis in organotypic cultures of type II pneumocytes. Biochim Biophys Acta. 1983;753:6-13.

17. Chung HR. Adrenal and thyroid function in the fetus and preterm infant. Korean $\mathrm{J}$ Pediatr. 2014;57:425-33.

18. Cuestas RA, Engel RR. Thyroid function in preterm infants with respiratory distress syndrome. J Pediatr. 1979;94:643-6.

19. Fisher DA, Polk DH. 2 - Development of the thyroid. Baillieres Clin Endocrinol Metab. 1989;3:627-57.

20. Fisher DA, Hobel CJ, Garza R, Pierce CA. Thyroid function in the preterm fetus. Pediatrics. 


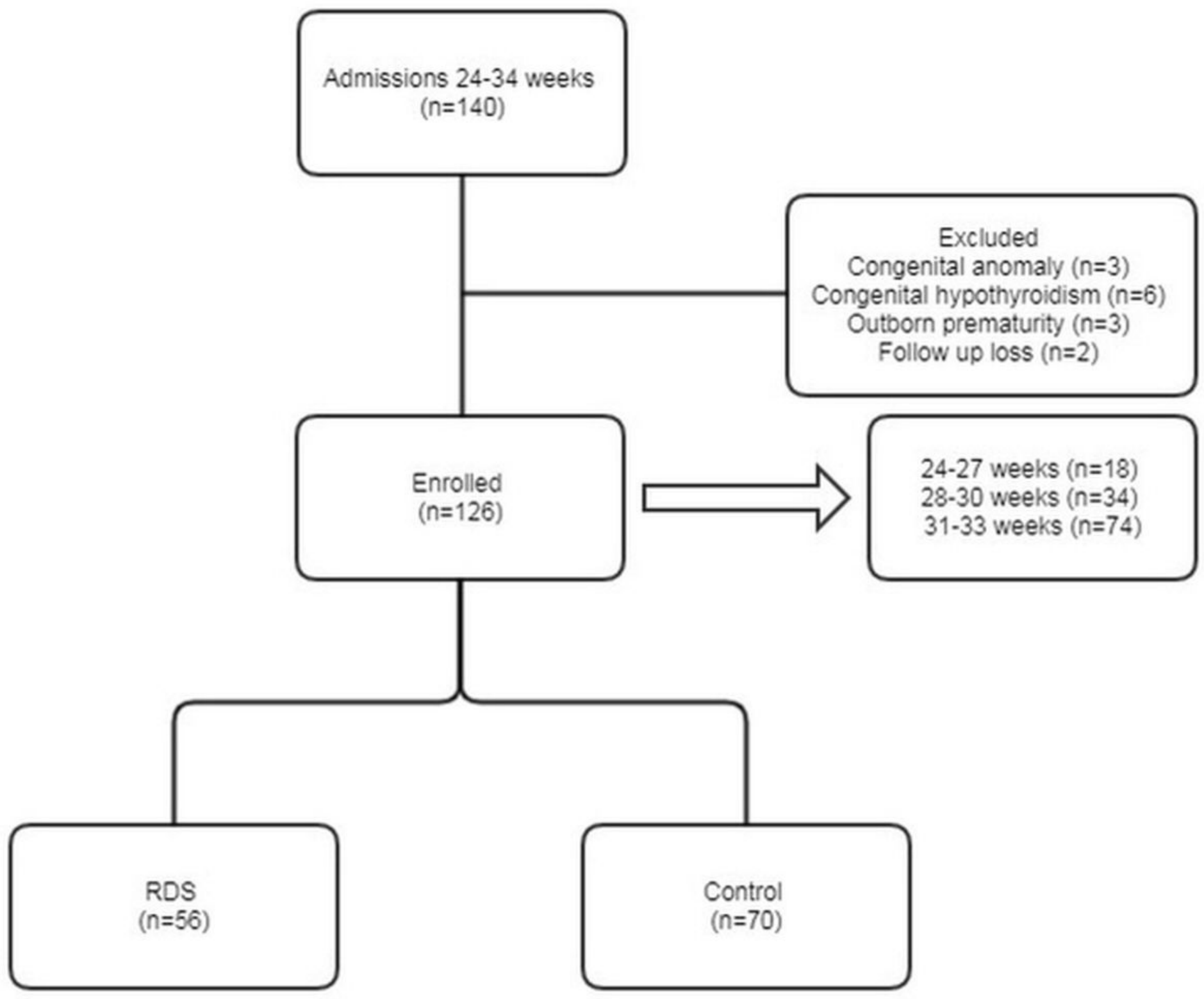

Figure 1

Study population.

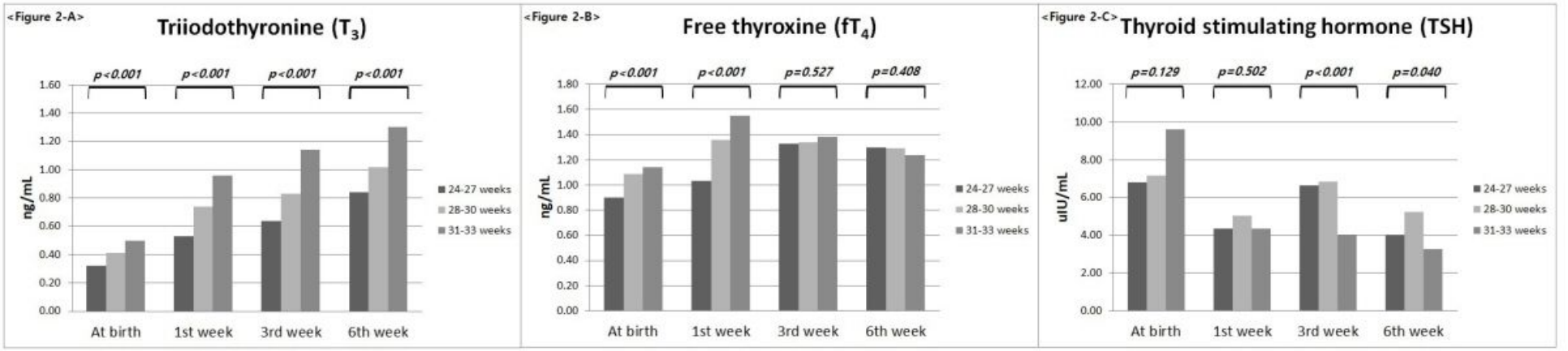

Loading [MathJax]/jax/output/CommonHTML/jax.js 


\section{Figure 2}

2-A. Triiodothyronine (T3) level was lower in groups with lower gestational age compared to other groups on the day of birth, and 1, 3 and 6 weeks after birth. 2-B. Free thyroxine (fT4) was significantly lower in the group with lower gestational age on the day of birth and 1 week after birth but there was no difference on the 3rd and 6th week after birth. 2-C. There was no difference in the thyroid stimulating hormone (TSH) level on the day of birth among the groups.

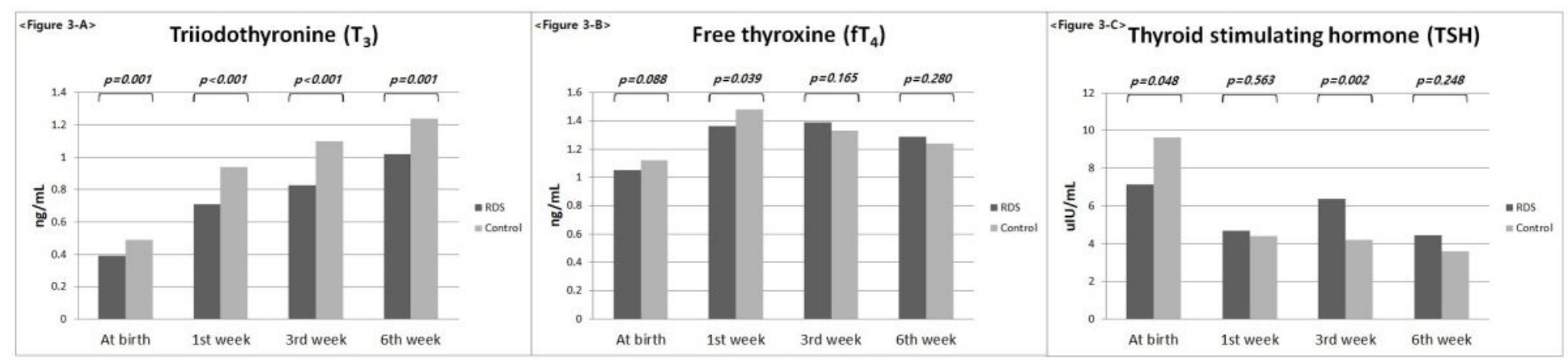

\section{Figure 3}

3-A. Triiodothyronine (T3) level showed an increase until 6 weeks after birth but the levels were lower in the RDS group compared with the control group on the day of birth, and 1, 3, and 6 weeks after birth. 3-B. Free thyroxine (fT4) level was higher in the control group on the day of birth but without any significant difference. On the 1 week after birth, fT4 was significantly lower in RDS group. 3-C. Thyroid stimulating hormone (TSH) level was higher in the RDS group on the day of birth but there was no significant difference 1 week after birth. 